\title{
Bi-directional acclimation of Cycas micronesica leaves to abrupt changes in incident light in understory and open habitats
}

\author{
T.E. MARLER ${ }^{+}$ \\ Western Pacific Tropical Research Center, College of Natural and Applied Sciences, University of Guam, \\ Mangilao, Guam, USA
}

\begin{abstract}
Leaf gas-exchange responses to shadefleck-sunfleck and sun-cloud transitions were determined for in situ Cycas micronesica K.D. Hill plants on the island of Guam to add cycads to the published gymnosperm data. Sequential sunfleckshadefleck transitions indicated understory leaves primed rapidly but open field leaves primed slowly. Time needed to reach $90 \%$ induction of net $\mathrm{CO}_{2}$ assimilation $\left(P_{\mathrm{N}}\right)$ was 2.9 min for understory leaves and 13.9 min for open field leaves. Leaf responses to sun-cloud transitions exhibited minimal adjustment of stomatal conductance, so $P_{\mathrm{N}}$ rapidly returned to precloud values following cloud-sun transitions. Results indicate bi-directional leaf acclimation behavior enables mature C. micronesica trees to thrive in deep understory conditions in some habitats and as emergent canopy trees in other habitats. These data are the first nonconifer gymnosperm data; the speed of gas-exchange responses to rapid light transitions was similar to some of the most rapid angiosperm species described in the literature.
\end{abstract}

Additional key words: cycad; dynamic leaf photosynthesis; fluctuating light; phenotypic plasticity; photosynthetic induction.

\section{Introduction}

Responses of plant photosynthetic organs to rapid transitions of light have been studied for decades (Pearcy and Way 2012). In understory settings, plants experience a background of diffuse light (often referred to as shadeflecks) that is limiting of carbon assimilation, and this diffuse light is frequently interrupted with sunflecks (lightflecks) that impose excessive light loads on the photosynthetic machinery. Although sunflecks are ephemeral, they account for an estimated $30-65 \%$ of total carbon gain of plants in understory habitats (Pearcy 1987, Chazdon 1988, Chazdon and Pearcy 1991, Pearcy 1990). The incident light level and duration of a sunfleck is defined by many factors such as cloud and wind conditions; canopy traits such as height, architecture, and leaf area index; leaf traits such as size and flutter; and the positioning of canopy interception and attenuation traits with respect to the diurnal solar track (Smith et al. 1989, Pearcy 1990, Brantley and Young 2010, Burgess et al. 2016). In large gaps or open habitats, photosynthetic organs must endure excessive irradiance and effectively respond to abrupt changes in incident light due to heterogeneous cloud cover (Knapp and Smith 1990a). Incident light level and duration of reduced light during cloud interception of sunlight is controlled by various factors such as the vertical distance through which the solar beam must pass through the cloud, horizontal size of the cloud, and wind speed at the elevation of the cloud.

Most data that have been used to develop canopy models for estimating forest carbon fluxes are from steady state light conditions (Porcar-Castell and Palmroth 2012, Way and Pearcy 2012). These models are inaccurate for predicting ecosystem carbon gain because of the strong influence of rapid light transitions on daily carbon gain at the leaf level. Recent efforts to improve modelling efforts have taken a comparative approach to identify common species traits that predict the relative efficiency of maintaining a beneficial carbon balance during the rapid light transitions. These studies have included traits such as

Received 26 November 2016, accepted 15 March 2017, published as online-first 26 April 2017.

${ }^{+}$Corresponding author; phone: 1-671-735-2130, fax: 1671-734-4600, e-mail: thomas.marler@gmail.com

Abbreviations: $E$ - transpiration; $g_{\mathrm{s}}$ - stomatal conductance to water; $\mathrm{IS}_{60 \mathrm{~s}}$ - photosynthetic induction state following 1 min of induction; $P_{\mathrm{N}}-$ net $\mathrm{CO}_{2}$ assimilation; $P_{\mathrm{N}}$ initial $-P_{\mathrm{N}}$ during initial diffuse light of shadeflecks; $P_{\mathrm{N} 60 \mathrm{~s}}-P_{\mathrm{N}}$ at 1 min induction; $P_{\mathrm{Nmax}}-\operatorname{maximum} P_{\mathrm{N}}$; $R_{\mathrm{D}}$ - dark respiration; $t_{50 \%}$ - time to reach $50 \%$ photosynthetic induction; $t_{90 \%}$ - time to reach $90 \%$ photosynthetic induction; WUE instantaneous water-use efficiency $\left(P_{\mathrm{N}} / E\right)$.

Acknowledgements: I thank Gil Cruz and Nirmala Dongol for support during field work. Support provided by the United States Department of the Navy, administered by the Naval Facilities Engineering Command Marianas, Guam. 
successional status, phylogeny, growth form, functional groups, leaf lifespan, extent of drought stress, and developmental growth conditions (Knapp and Smith 1990a,1990b; Kursar and Coley 1993, Bai et al. 2008, Pearcy and Way 2012).

The collective efforts to delineate universal themes that accurately predict leaf responses to sunflecks are plagued by contrasting results. This is not surprising, since little overlap occurs among the adaptive traits that maximize $\mathrm{CO}_{2}$ assimilation, traits that maximize water-use efficiency, traits that mitigate photoinhibition, and traits that minimize thermal damage (Knapp and Smith 1989, 1990a, 1990b; Porcar-Castell and Palmroth 2012, Way and Pearcy 2012). Adjustments of these traits during changing environmental cues are asynchronous and hysteresis disallows induction and relaxation similarities. The use of closely related species in studies of photosynthetic response to contrasting light environments is highly useful because the genetic relationships of the species are known (Goldstein et al. 2016). This approach was used with a robust comparison of many Glycine max (L.) Merr. genotypes which revealed no relationship between photosynthetic capacity and photosynthetic induction response (Soleh et al. 2017).

Bai et al. (2008) suggested that the contrasting responses to sunflecks illuminated in reviews and metaanalyses may be due to the inadequate collective body of information to date. In order to expand the case studies on phylogeny, ferns and gymnosperms have been added to the global data set (Naumburg and Ellsworth 2000, Zhang et al. 2009, Vico et al. 2011, McAusland et al. 2016) and their comparison with angiosperms may aid in understanding if currently observed adaptations of physiological mechanisms to incident light heterogeneity are ancient plant traits. However, all of the gymnosperm model species in studies conveying unambiguous results have been conifers, and three of the four divisions of gymnosperms have been ignored during the decades of accumulating case studies. This is unfortunate because cycads comprise a sister group to all other gymnosperms (Garcia and Kovařík 2013), which also indicates that cycads are a sister group to all other spermatophytes (Brenner et al. 2003). This void in phylogenetic representation limits the utility of the data inputs for validating models and improving understanding of general concepts with regard to photobiology of plants in heterogeneous environments.

Cycads comprise a key relict plant lineage. Considering that they have persisted throughout the eons (Norstog and Nicholls 1997), remain represented by 10 genera and almost 350 extant species (Calonje et al. 2016), and comprise one of the most threatened contemporary plant groups (Brummitt et al. 2015, Fragniere et al. 2015), the fact that they have been largely ignored in recent plant research is odd (Brenner et al. 2003). The literature on photosynthetic traits of cycads is minimal, and can be summarized as species surveys of light-saturated maximum photosynthesis (Marler and Willis 1997, Brodribb et al. 2007, Zhang et al. 2015), in situ measurements of leaf photosynthesis for Dioon sonorense (De Luca, Sabato \& Vázq.Torres) J.Chemnick, T.J.Gregory \& S.Salas-Mor. and Zamia skinneri Warsz. ex A. Dietr. (Clark et al. 1992, Álvarez-Yépiz et al. 2014b), photosynthetic light-response curves for D. sonorense (Álvarez-Yépiz et al. 2014a) and C. micronesica (Marler 2007), diurnal response curves for C. micronesica (Marler 2004) and Zamia furfuracea L.f. (Marler and Willis 1997), the influence of developmental light level on C. micronesica leaf photosynthesis (Marler 2004), and the influence of leaf age on C. micronesica photosynthesis (Marler 2007).
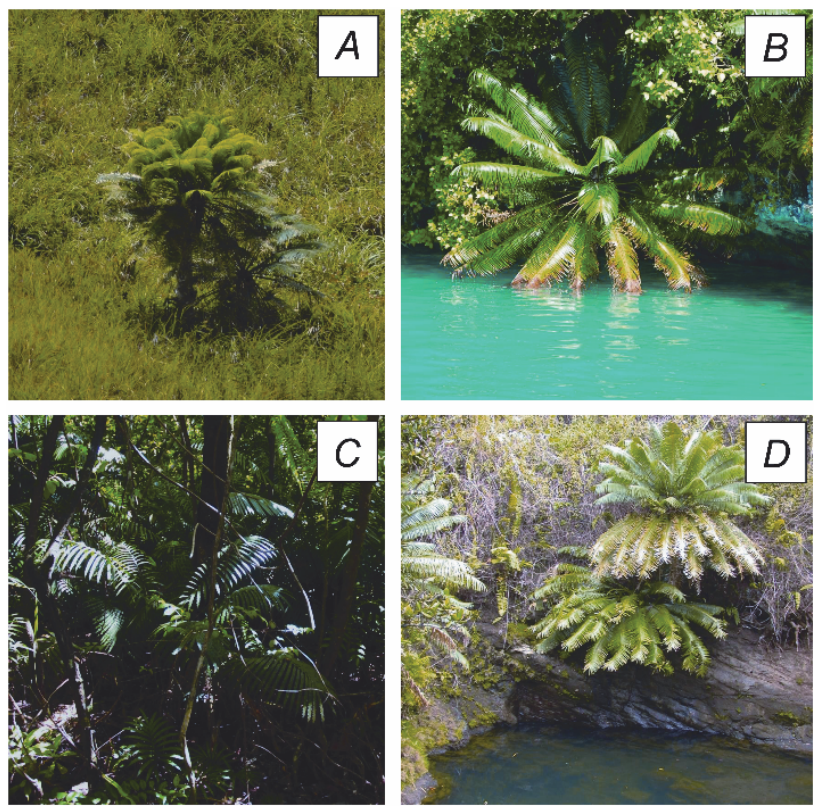

Fig. 1. Cycas micronesica thrives in highly diverse niche habitats. (A) In savanna grasslands on volcanic soils, the trees grow in full sun conditions. $(B)$ In littoral habitats on coralline soils, the plants are exposed to acute saline conditions. $(C)$ In understory habitats, the plants thrive with limited incident light punctuated by numerous sunflecks. $(D)$ In deep ravine riparian habitats no direct sunlight reaches the leaves and diffuse light sustains plant health.

The objective here was to determine the induction and relaxation dynamics of gas-exchange responses to abrupt changes in incident light for a representative cycad taxon to determine how the results fit into the published data for gymnosperms. More has been published on the leaf photosynthetic behavior of $C$. micronesica than any other cycad species, and the species does not express an obligate predilection for any ecological or successional niche (Fig. 1). Moreover, conservation of this endangered species (Marler et al. 2010) is hindered by the lack of empirical information to improve management decisions. Therefore, this species was selected as the model species. 


\section{Materials and methods}

Characterizing sunfleck use by $C$. micronesica was accomplished in a habitat containing an in situ conservation management plot on the east coast of Guam (Plot C in Marler et al. 2016). Incident light conditions in this habitat were characterized on several sunny days in June 2014. A 1-m line photosynthetically active radiation quantum sensor (EMS 7, PP Systems, USA) was used to determine integrated PFD, which ranged from 250 to 400 $\mu$ mol(photon) $\mathrm{m}^{-2} \mathrm{~s}^{-1}$ at the height of the understory plants that served as experimental units. PFD of shadeflecks was measured with a Skye SKP 200 quantum sensor (Skye Instruments, Llandrindod Wells, Powys, UK), and shadeflecks ranged from 55 to $78 \mu$ mol(photon) $\mathrm{m}^{-2} \mathrm{~s}^{-1}$. Ten trees that were $1-2 \mathrm{~m}$ in height were selected in the understory habitat, and ten trees of the same height range were selected in open fields in the same habitat.

Leaflet gas-exchange traits were measured with a portable open-flow system (CIRAS-2, PP Systems, USA) fitted with a PLC6 $(U)$ cuvette on mornings from 27 July 2014 to 5 August 2014. The plants were well-watered, as the daily rainfall mean was $24.3 \mathrm{~mm}$ for the week prior to measurements (www.wunderground.com). Control of the incident light prior to measurements was accomplished by covering each of the 20 experimental trees with a tarpaulin the evening prior to the measurements in a manner that excluded all direct and reflected light. Loading the leaflets in the cuvette was accomplished in accordance with Marler and Willis (1997). Leaf gas-exchange measurements were accomplished between 07:00 and 10:00 h. The reference $\mathrm{CO}_{2}$ concentration during measurements was $400 \mu \mathrm{mol}$ $\mathrm{mol}^{-1}$, air flow rate was $250 \mathrm{ml} \mathrm{min}^{-1}$, chamber temperature was $28-29^{\circ} \mathrm{C}$, and vapor pressure deficit was 1.1-1.2 $\mathrm{kPa}$. Three gas-exchange response traits were quantified on each experimental tree. The first measurement was conducted in the darkness provided by the tarpaulin, and was recorded as dark respiration $\left(R_{\mathrm{D}}\right)$. Thereafter, the tarpaulin was loosened and positioned to allow diffuse incident light to reach the experimental leaves, but to block the solar beam. The plants were allowed to adjust to the diffuse light conditions [PFD of $65.4 \pm 2.45 \mu \mathrm{mol}$ (photon) $\mathrm{m}^{-2} \mathrm{~s}^{-1}$ ] for $30 \mathrm{~min}$ before the second measurement was conducted on a different set of leaflets. This measurement characterized the induction traits during a series of sunflecks. Photosynthetic induction is used herein as the increase in carbon gain following an abrupt increase in PFD resulting from increased function of Calvin cycle enzymes and buildup of metabolic pools, and priming is used as the ability of one sunfleck to increase a leaf's induction status in a subsequent sunfleck. Diffuse light shadeflecks were interrupted with sunflecks with PFD of $c a .800 \mu \mathrm{mol}$ (photon) $\mathrm{m}^{-2} \mathrm{~s}^{-1}$ provided by a $12-\mathrm{V}$ light bank consisting of fluorescent and quartz halogen bulbs. The leaflets were maintained in the cuvette for ca. 5 min until steady state gas exchange, then data were recorded every $20 \mathrm{~s}$ throughout $c a .23 \mathrm{~min}$ with sunflecks of $60 \mathrm{~s}$ and shadeflecks of $120 \mathrm{~s}$. A total of seven sunflecks were supplied. This controlled approach bypassed the statistical difficulties generated by heterogeneous sunfleck incident light and duration under ambient sunflecks. The third measurement was conducted on another set of leaflets to determine the induction traits following the transition from steady state diffuse light to $16 \mathrm{~min}$ at PFD of $800 \mu \mathrm{mol}$ (photon) $\mathrm{m}^{-2} \mathrm{~s}^{-1}$ supplied by the 12-V light bank.

Photosynthetic induction curves were fitted by a NLIN procedure of the $S A S 9.1$ statistical software package ( $S A S$ Institute, Cary, NC) by designating the shade-sunfleck transition as time $=0$ and using the model $P_{\mathrm{N}}=$ a $\left(1-\mathrm{e}^{-\mathrm{b}^{*} \text { time }}\right)$, where $P_{\mathrm{N}}-$ net $\mathrm{CO}_{2}$ assimilation, $\mathrm{a}-$ the asymptote indicating full induction, and $\mathrm{b}$ - the rate of approach to the asymptote. A curve was fitted to each replication, generating 10 models for understory leaves and 10 models for sun leaves. Differences between understory and sun leaves were determined by unpaired $t$-test, and response traits included $R_{\mathrm{D}}$, the model parameters a and $\mathrm{b}, P_{\mathrm{N}}$ during initial diffuse light $\left(P_{\text {Ninitial }}\right), P_{\mathrm{N}}$ at $1 \mathrm{~min}$ induction $\left(P_{\mathrm{N} 60 \mathrm{~s}}\right)$, maximum $P_{\mathrm{N}}\left(P_{\mathrm{Nmax}}\right)$, the time to reach $50 \%$ induction $\left(t_{50 \%}\right)$, and the time to reach $90 \%$ induction $\left(t_{90} \%\right)$. The induction state $(\%)$ following $1 \mathrm{~min}$ of induction ( $\mathrm{IS}_{60 \mathrm{~s}}$ ) was calculated and differences between understory and sun leaves were determined by the nonparametric, nonassuming, and distribution-free Kolmogorov-Smirnov two-sample test.

Characterizing $C$. micronesica leaf gas-exchange responses to sun-cloud-sun transitions was attempted for the ten trees in open fields beginning 6 August 2014. Stochastic PFD and duration of cloud transitions caused difficulty in repeating methods from tree to tree. Therefore, the methods of Clemente and Marler (1996) were employed for this purpose and accomplished in a second conservation management plot in central Guam (Plot B in Marler et al. 2016) on clear days in January 2015. The plants had received a daily average of $21.9 \mathrm{~mm}$ of rainfall during the week prior to measurements. In brief, sun-cloud transitions were simulated by placement of neutral density shade cloth placed over the cuvette, and cloud-sun transitions were simulated by removal of the shade cloth. Duration of the cloud cover was standardized to $3 \mathrm{~min}$, PFD of sun conditions ranged from 1,950 to 2,250 $\mu$ mol(photon) $\mathrm{m}^{-2} \mathrm{~s}^{-1}$, and PFD of cloud cover ranged 295 to $335 \mu \mathrm{mol}$ (photon) $\mathrm{m}^{-2} \mathrm{~s}^{-1}$. These values matched measurements of typical PFD under Guam's natural cloud transitions. Leaf gas-exchange measurements were accomplished on ten trees and were restricted between 10:00 and 12:30 h. The reference $\mathrm{CO}_{2}$ concentration during measurements was $400 \mu \mathrm{mol} \mathrm{mol}^{-1}$, air flow rate was $250 \mathrm{ml} \mathrm{min}^{-1}$, chamber temperature was $30-32^{\circ} \mathrm{C}$, and vapor pressure deficit was 1.6-2.0 $\mathrm{kPa}$. Data 
acquisition was initiated after the leaflets reached steady state gas exchange under full sun conditions, were recorded at 20-s intervals through the sun-cloud and cloud-sun transitions, and continued until steady state conditions were reached following the cloud-sun transition. Leaf age influences photosynthesis of this species (Marler 2007). Overlapping cataphylls are produced following each leaf flush in this species, and these cataphylls protect the massive primary thickening meristem and stem apex during the quiescent period that follows each leaf pulse. They persist between each cohort of leaves, rendering the designation of successive leaf age groups unambiguous. Measurements were conducted on the youngest cohort of leaves and the oldest cohort of leaves on each tree.

Sun-cloud gas-exchange responses were quantified by the system as $P_{\mathrm{N}}$, stomatal conductance to water $\left(g_{\mathrm{s}}\right)$, transpiration $(E)$, and instantaneous water-use efficiency (WUE, defined by the quotient $P_{\mathrm{N}} / E$ ). Differences between young and old leaves for steady state $P_{\mathrm{N}}, g_{\mathrm{s}}, E$, and WUE were determined by unpaired $t$-test. The influence of leaf age on the percent decline of $P_{\mathrm{N}}, g_{\mathrm{s}}, E$, and WUE during cloud cover was determined by the Kolmogorov-Smirnov test.

\section{Results}

Sunflecks: Cycas micronesica leaves from understory trees exhibited $R_{\mathrm{D}}$ that was $79 \%$ of that for leaves from open field trees (Table 1). Leaves from both habitats exhibited sunfleck priming, where each sunfleck improved the ability of the leaf to utilize the subsequent sunfleck (Fig. 2). Leaves from understory trees were able to reach maximum photosynthetic use of 1-min sunflecks after only two priming sunflecks. In contrast, leaves from open field trees required five priming sunflecks before reaching maximum photosynthetic use of 1-min sunflecks. The level of photosynthetic induction at $40 \mathrm{~s}$ into each successive sunfleck exhibited a different pattern. The full sun leaves reached a stagnation in induction status at $40 \mathrm{~s}$ by the third sunfleck, but the understory leaves were able to increase induction status at $40 \mathrm{~s}$, without a concomitant increase in induction status at $1 \mathrm{~min}$, until the sixth sunfleck.

Leaves from understory plants exhibited faster rates of induction but lower maximum $P_{\mathrm{N}}$ than leaves from open field plants (Fig. 3, Table 1). The rate of approach to the asymptote for understory leaves was 4.8 -fold greater than for full sun leaves (Table 1). Leaves from understory trees exhibited $P_{\mathrm{N} 60 \mathrm{~s}}$ that was twice that of leaves from open field trees. Similarly, $\mathrm{IS}_{60 \text { s }}$ was 3.7 -fold greater for understory leaves than for open field leaves. The time required for $50 \%$ induction of understory leaves was $22 \%$ of that for open field leaves, and the time required for $90 \%$ induction of understory leaves was $21 \%$ of that for open field leaves. Shadefleck $P_{\text {Ninitial }}$ of understory leaves was 2.1-fold greater than that for open field leaves (Table 1).

The 1-min sequential sunflecks (Fig. 2) were able to prime understory leaves to $c a .80 \%$ of full induction (Fig. 3). In contrast, these sunflecks primed open field leaves to only $45 \%$ of full induction. After $40 \mathrm{~s}$ into each sunfleck, the understory leaves were able to reach $c a$. 70\% of full induction, but the open field leaves were only able to reach $c a$. $20 \%$ of full induction.

Sun-cloud transitions: Young $C$. micronesica leaf $P_{\mathrm{N}}$ was about $9 \mu \mathrm{mol} \mathrm{m} \mathrm{m}^{-2} \mathrm{~s}^{-1}$ in full sun conditions, and declined about $15 \%$ within 20 s of the sun-cloud transition (Fig. 4A). Leaf $P_{\mathrm{N}}$ during cloud cover stabilized after $40 \mathrm{~s}$. Old leaf $P_{\mathrm{N}}$ was about $7 \mu \mathrm{mol} \mathrm{m} \mathrm{m}^{-2} \mathrm{~s}^{-1}$ in full sun conditions, then declined about $45 \%$ within $20 \mathrm{~s}$ of the sun-cloud

Table 1. Characteristics of Cycas micronesica leaf physiology during photosynthetic induction as influenced by development in understory conditions or open field conditions. Dark respiration $\left(R_{\mathrm{D}}\right)$ and net photosynthesis in diffuse light $\left(P_{\text {Ninitial }}\right)$ were based on net $\mathrm{CO}_{2}$ assimilation in darkness and photon flux density (PFD) of $c a .65 \mu$ mol(photon) $\mathrm{m}^{-2} \mathrm{~s}^{-1}$. Variable a is asymptote and variable $\mathrm{b}$ is rate of approach to the asymptote for the models that defined photosynthetic induction. Net photosynthesis at 1-min induction $\left(P_{\mathrm{N} 60 \mathrm{~s}}\right)$, the time to reach $50 \%$ induction $\left(t_{50 \%}\right)$, the time to reach $90 \%$ induction $\left(t_{90 \%}\right)$, and maximum $P_{\mathrm{N}}\left(P_{\mathrm{Nmax}}\right)$ were based on net $\mathrm{CO}_{2}$ assimilation following supply of PFD of $800 \mu \mathrm{mol}\left(\right.$ photon) $\mathrm{m}^{-2} \mathrm{~s}^{-1}$. The induction state following 1 min of induction (IS $60 \mathrm{~s}$ ) was calculated as $\left(P_{\mathrm{N} 60 \mathrm{~s}} / P_{\mathrm{Nmax}}\right) \times 100$. Mean $\pm \mathrm{SE}, n=10$. $t$ - unpaired $t$-test; $D$-nonparametric Kolmogorov-Smirnov two-sample test.

\begin{tabular}{lllll}
\hline Variable & Understory & Open field & Statistics & Significance \\
\hline$R_{\mathrm{D}}\left[\mu \mathrm{mol} \mathrm{m}{ }^{-2} \mathrm{~s}^{-1}\right]$ & $0.91 \pm 0.01$ & $1.15 \pm 0.03$ & $t=7.723$ & $P<0.001$ \\
$\mathrm{a}\left[\mu \mathrm{mol} \mathrm{m}^{-2} \mathrm{~s}^{-1}\right]$ & $5.06 \pm 0.02$ & $9.13 \pm 0.15$ & $t=27.875$ & $P<0.001$ \\
$\mathrm{~b}\left[\mathrm{~min}^{-1}\right]$ & $0.806 \pm 0.02$ & $0.168 \pm 0.006$ & $t=28.132$ & $P<0.001$ \\
$P_{\text {Ninitial }}\left[\mu \mathrm{mol} \mathrm{m}^{-2} \mathrm{~s}^{-1}\right]$ & $0.85 \pm 0.021$ & $0.40 \pm 0.01$ & $t=27.089$ & $P<0.001$ \\
$P_{\mathrm{N} 60 \mathrm{~s}}\left[\mu \mathrm{mol} \mathrm{m} \mathrm{s}^{-1}\right]$ & $2.80 \pm 0.03$ & $1.41 \pm 0.02$ & $t=31.241$ & $P<0.001$ \\
$t_{50 \%}[\mathrm{~min}]$ & $0.9 \pm 0.1$ & $4.1 \pm 0.4$ & $t=23.215$ & $P<0.001$ \\
$t_{90 \%}[\mathrm{~min}]$ & $2.9 \pm 0.1$ & $13.9 \pm 0.5$ & $t=21.809$ & $P<0.001$ \\
$P_{\mathrm{Nmax}}\left[\mu \mathrm{mol} \mathrm{m} \mathrm{m}^{-2} \mathrm{~s}^{-1}\right]$ & $5.07 \pm 0.06$ & $8.07 \pm 0.12$ & $t=22.651$ & $P<0.001$ \\
$\mathrm{IS}_{60 \mathrm{~s}}[\%]$ & $55 \pm 2$ & $15 \pm 1$ & $D=1.000$ & $P<0.001$ \\
\hline
\end{tabular}




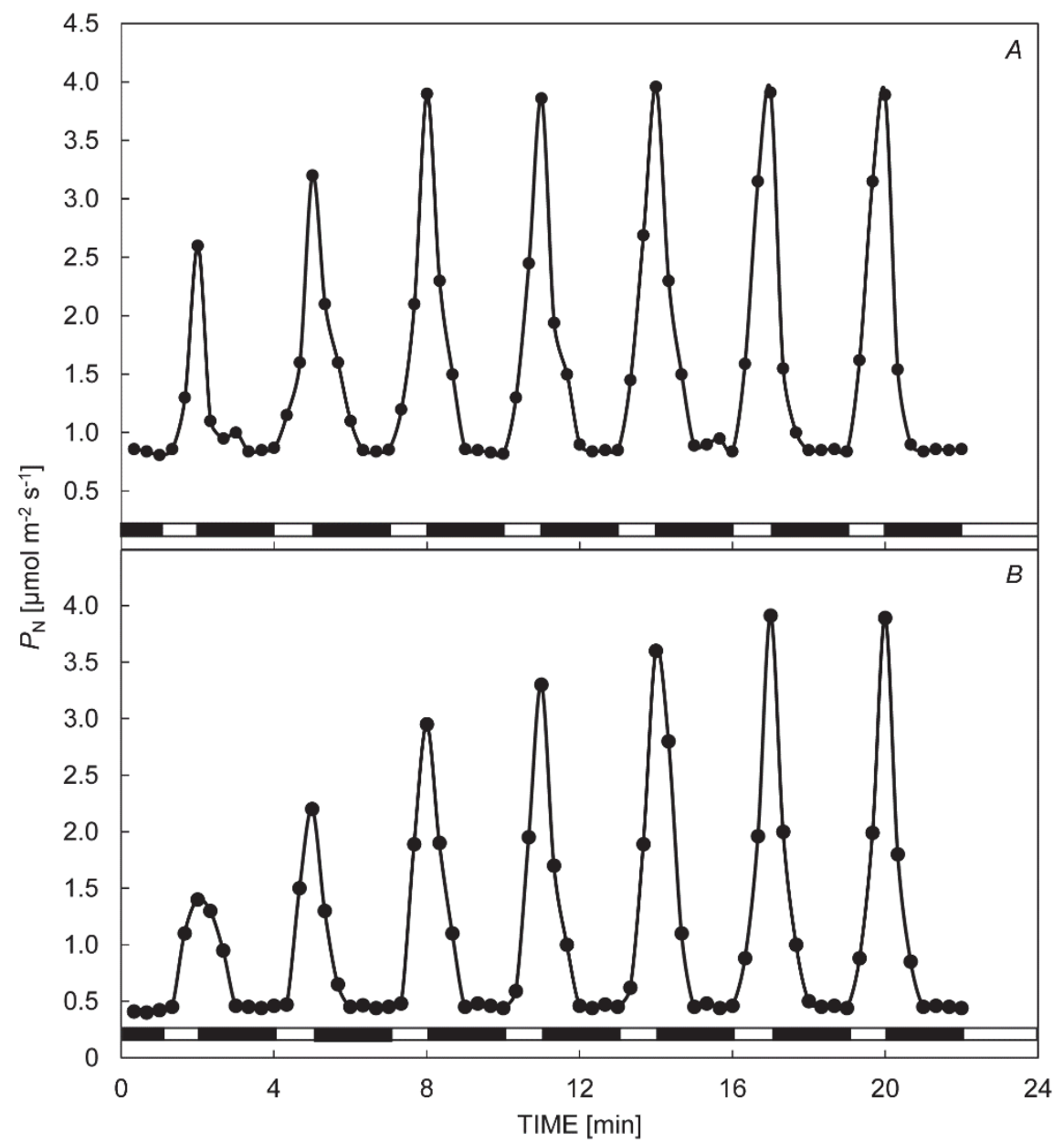

Fig. 2. Net $\mathrm{CO}_{2}$ assimilation $\left(P_{\mathrm{N}}\right)$ of Cycas micronesica leaves in response to alternating shadeflecks with PFD of $c a$. $65 \mu \mathrm{mol}(\mathrm{photon})$ $\mathrm{m}^{-2} \mathrm{~s}^{-1}$ (dark sections on bar adjacent to x-axis) and sunflecks with PFD of $c a .800 \mu$ mol(photon) $\mathrm{m}^{-2} \mathrm{~s}^{-1}$. (A) Plants growing in understory conditions with heterogeneous incident light. $(B)$ Plants growing in open fields. Each marker is a mean of ten replications.

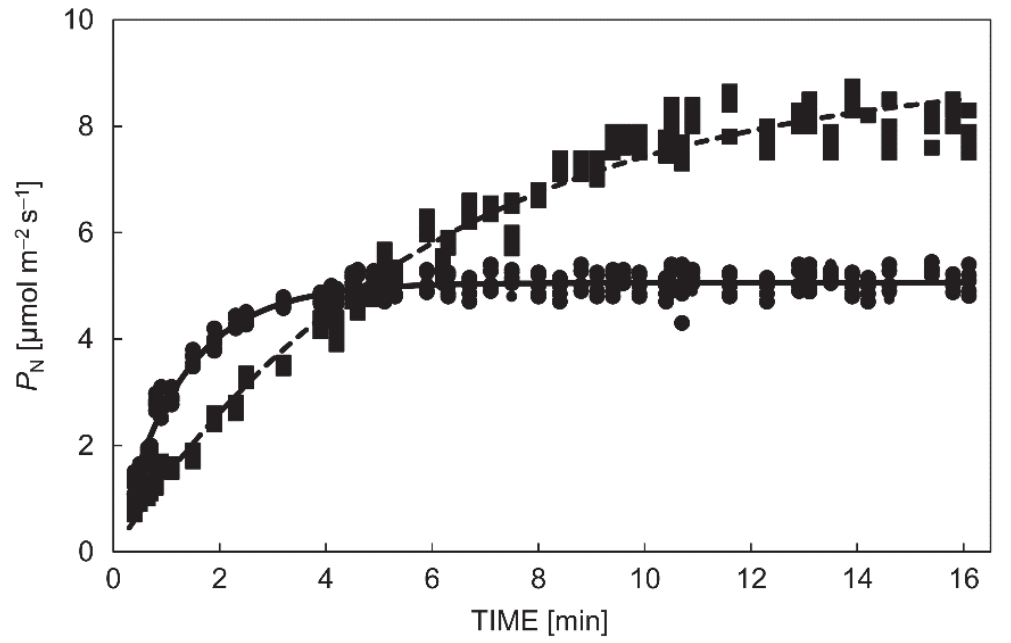

Fig. 3. Net $\mathrm{CO}_{2}$ assimilation $\left(P_{\mathrm{N}}\right)$ of Cycas micronesica leaves following transition of photon flux density of $c a$. 65 to $c a .800 \mu \mathrm{mol}\left(\right.$ photon) $\mathrm{m}^{-2} \mathrm{~s}^{-1}$. Square markers and dashed line are from open field plants $\left[P_{\mathrm{N}}=9.13\left(1-\mathrm{e}^{-0.168^{*} \mathrm{~min}}\right)\right]$, circles and solid line $\left[P_{\mathrm{N}}=5.06\left(1-\mathrm{e}^{-0.806 * \mathrm{~min}}\right)\right]$ are from understory plants. transition. Leaf $P_{\mathrm{N}}$ for both age groups increased rapidly after the cloud-sun transition and returned to precloud $P_{\mathrm{N}}$ within $40 \mathrm{~s}$ (Fig. $4 A$ ). Full sun $P_{\mathrm{N}}$ differed but the percent decline in $P_{\mathrm{N}}$ during cloud cover did not differ between the two age groups (Table 2). Full sun leaf $g_{\mathrm{s}}$ of old leaves was about $87 \%$ of that for young leaves (Fig. $4 B$, Table 2). The decline in $g_{s}$ following the sun-cloud transition was sluggish and minimal. By the end of 3-min of cloud cover 


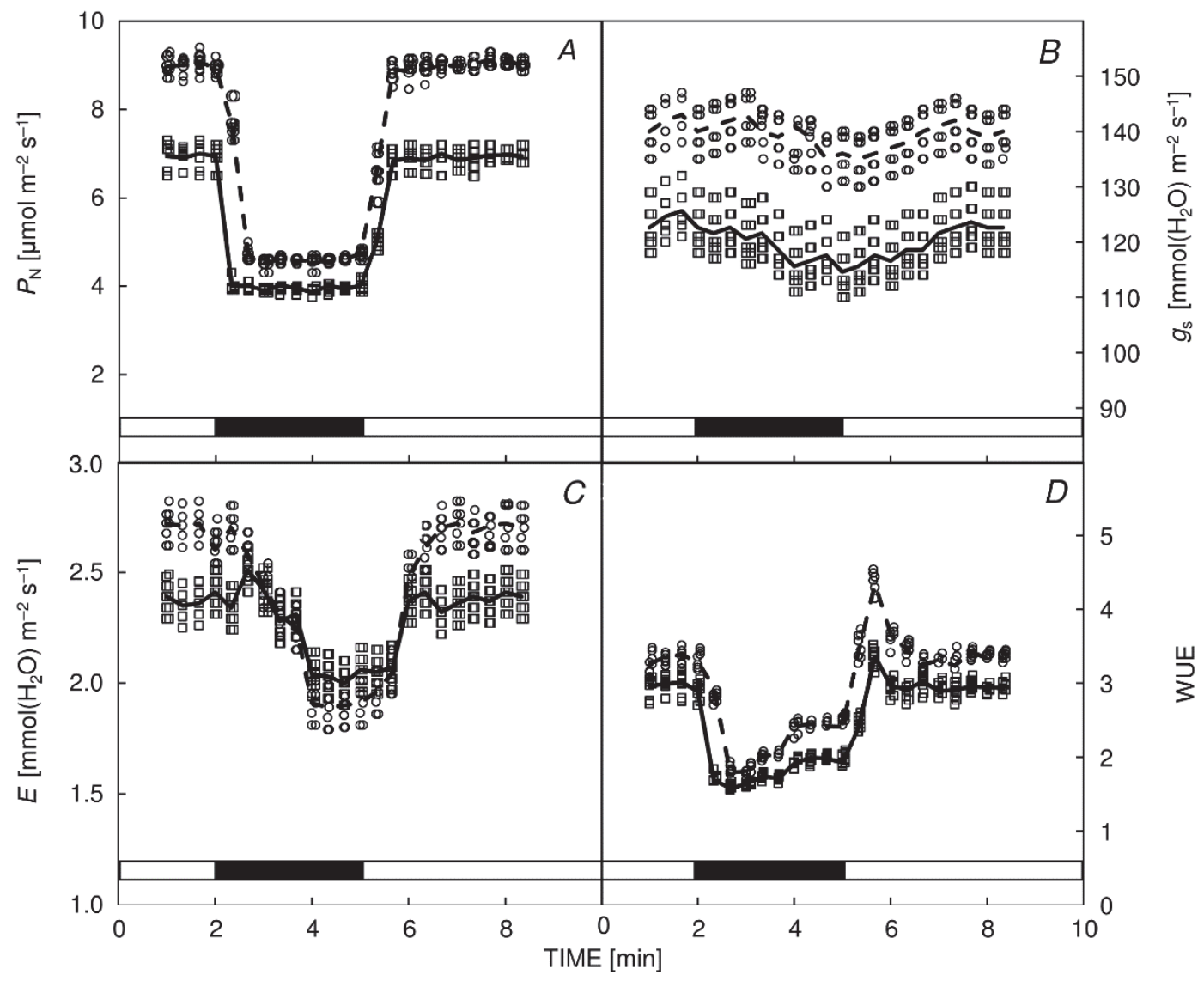

Fig. 4. Response of net $\mathrm{CO}_{2}$ assimilation $(A)$, stomatal conductance $(B)$, transpiration $(C)$, and instantaneous water-use efficiency $(D)$ of Cycas micronesica leaves. The dark sections on the bar adjacent to x-axis designate 3 min at PFD of 295-335 $\mu$ mol(photon) $\mathrm{m}^{-2} \mathrm{~s}^{-1}$, the white sections were characterized by PFD of 1,850-2,100 $\mu \mathrm{mol}$ (photon) $\mathrm{m}^{-2} \mathrm{~s}^{-1}$. Circles and dashed line depict the youngest leaf cohort, square markers and solid line depict the oldest leaf cohort.

Table 2. Characteristics of Cycas micronesica leaf physiology during sun-cloud transitions. Sun conditions ranged from photon flux density (PFD) of 1,950 to $2,250 \mu \mathrm{mol}$ (photon) $\mathrm{m}^{-2} \mathrm{~s}^{-1}$, and cloud cover for $3 \mathrm{~min}$ ranged from 295 to $335 \mu \mathrm{mol}(\mathrm{photon}) \mathrm{m}^{-2} \mathrm{~s}^{-1}$. Net $\mathrm{CO}_{2}$ assimilation $\left(P_{\mathrm{N}}\right)$, stomatal conductance $\left(g_{\mathrm{s}}\right)$, transpiration $(E)$, and instantaneous water-use efficiency WUE $\left(P_{\mathrm{N}} / E\right)$ were from steady-state gas exchange in full sun conditions. Decline of each variable was the decrease that occurred during the 3-min cloud cover. Mean $\pm \mathrm{SE}, n=10$. $t$ - unpaired $t$-test; $D$ - nonparametric Kolmogorov-Smirnov two-sample test.

\begin{tabular}{lllll}
\hline Variable & Young & Old & Statistics & Significance \\
\hline$P_{\mathrm{N}}\left[\mu \mathrm{mol} \mathrm{m}{ }^{-2} \mathrm{~s}^{-1}\right]$ & $8.99 \pm 0.06$ & $6.91 \pm 0.08$ & $t=21.143$ & $P<0.001$ \\
Decline $[\%]$ & $53.6 \pm 1.0$ & $55.3 \pm 0.8$ & $D=0.300$ & $P=0.675$ \\
$g_{\mathrm{s}}\left[\mathrm{mmol}\left(\mathrm{H}_{2} \mathrm{O}\right) \mathrm{m}^{-2} \mathrm{~s}^{-1}\right]$ & $141.1 \pm 4.3$ & $122.5 \pm 4.9$ & $t=28.404$ & $P<0.001$ \\
Decline $[\%]$ & $95.7 \pm 0.4$ & $93.6 \pm 0.4$ & $D=0.300$ & $P=0.675$ \\
$E\left[\mathrm{mmol}\left(\mathrm{H}_{2} \mathrm{O}\right) \mathrm{m}^{-2} \mathrm{~s}^{-1}\right]$ & $2.68 \pm 0.03$ & $2.39 \pm 0.02$ & $t=9.077$ & $P<0.001$ \\
Decline $[\%]$ & $70.7 \pm 0.6$ & $83.7 \pm 0.7$ & $D=1.000$ & $P<0.001$ \\
WUE & $3.25 \pm 0.04$ & $3.03 \pm 0.05$ & $t=3.884$ & $P<0.005$ \\
Decline [\%] & $54.7 \pm 0.5$ & $52.4 \pm 0.9$ & $D=0.500$ & $P=0.111$ \\
\hline
\end{tabular}

the $g_{\mathrm{s}}$ of young leaves remained at about $96 \%$ of that prior to the sun-cloud transitions. The old leaves behaved similarly, as $g_{\mathrm{s}}$ under cloud cover was $c a$. $94 \%$ of that under full sun. Leaf $E$ was greater for young leaves than for old leaves, and response to cloud cover was sluggish
(Fig. 4C, Table 2). Leaf $E$ was similar for the two age categories during the cloud cover, so the percent decline in $E$ was dissimilar (Table 2). Leaf $E$ increased slowly after the cloud-sun transition, stabilized for old leaves after about $1 \mathrm{~min}$, and stabilized for young leaves after about 
2 min (Fig. 4C). The declined in $E$ during cloud cover paralleled leaf temperature. Maximum leaf temperature in full sun was $32.7^{\circ} \mathrm{C}$ for young leaves, and declined to $30.6^{\circ} \mathrm{C}$ by the end of 3-min cloud cover. Similarly, maximum leaf temperature in full sun was $32.8^{\circ} \mathrm{C}$ for old leaves, and declined to $30.9^{\circ} \mathrm{C}$ by the end of 3 -min cloud cover. WUE of the two leaf age categories differed under full sun conditions, but the relative decline in WUE during cloud cover did not differ (Table 2). The interactions

\section{Discussion}

Recent literature reviews concluded that gymnosperms exhibited slower induction responses to sunflecks than angiosperms (Naumburg and Ellsworth 2000, Vico et al. 2011). However, gymnosperms were represented exclusively by temperate zone woody conifer taxa. This report of $C$. micronesica leaf behavior augments the global database with the first nonconifer, tropical, nonwoody gymnosperm, and the results indicate that previous assertions were not fully accurate. For example, $t_{90 \%}$ of understory $C$. micronesica leaves was within the range of the most rapid angiosperm species and was 14.6-fold more rapid than the mean for the reviewed conifers in Naumburg and Ellsworth (2000).

These results reveal that use of the term gymnosperm for the spermatophyte group comparisons in past reviews was misleading because the data failed to include nonconifer gymnosperms. The goal to understand the extent to which photosynthetic induction of gymnosperms differs from that of angiosperms cannot be accurately reached unless representatives from the Cycadidae, Ginkgoidae, and Gnetidae are added to the published conifer database. One recent addition to the literature included Ginkgo biloba L. data (McAusland et al. 2016). Unfortunately, the environmental conditions of the plants and developmental light conditions of the experimental leaves prior to data collection were absent from the methods, so the data are not suitable for comparison to the literature.

Under the conditions of this study, C. micronesica leaves that developed in understory conditions possessed a competitive advantage over leaves that developed in large gaps or open fields for exploiting the high light pulses in heterogeneous incident light conditions. This was borne out not only in the percent of $P_{\mathrm{Nmax}}$ for each leaf type that was reached during sequential 1-min pulses of light, but also in absolute $P_{\mathrm{N}}$ during the ephemeral periods of high light (Figs. 2, 3). This advantage would extend up to a theoretical sunfleck duration of $c a .5 \mathrm{~min}$, as this was the time when the two induction models for $P_{\mathrm{N}}$ intersected and the open field leaves began to exhibit greater $P_{\mathrm{N}}$ than the understory leaves. Designing the photosynthetic machinery to efficiently use the short durations of high light clearly came at a cost, as photosynthetic capacity for understory leaves in a fully induced state was suppressed to $55 \%$ of that for full sun leaves (Fig. 3). between the dynamic changes in $P_{\mathrm{N}}$ and $E$ caused concomitant changes in WUE to exhibit post-cloud dynamics that were unique. The rapid increase in $P_{\mathrm{N}}$ and slow increase in $E$ caused WUE to increase dramatically within $20 \mathrm{~s}$ of the cloud-sun transition, then further increase to levels that exceeded the precloud levels within $40 \mathrm{~s}$ (Fig. 4D). WUE of old leaves stabilized to precloud levels by about $60 \mathrm{~s}$ after the cloud-sun transition, and of young leaves stabilized by about $100 \mathrm{~s}$ after the cloud-sun transition.

Ecologists are interested in understanding fundamental mechanisms that explain ecological phenomena to illuminate a holistic perspective of a subject. Toward this end, sunfleck research has been crafted around the prediction that understory plants should be more efficient in using and exhibit greater dependence on sunflecks than large gap or open habitat plants, and species groupings such as growth form or successional status will exhibit similarities in the response traits. The results reported here from the first cycad species to be studied add to the many reports that have verified this prediction (Küppers et al. 1996, Chen and Klinka 1997, Pearcy and Way 2012). However, other reports have generated confusion with findings that fail to conform to these predictions (Han et al. 1999, Urban et al. 2007, Pearcy and Way 2012). Addressing research questions with this understory bias minimizes the value of the adaptive repertoire of the model species by approaching the adaptation as a unidirectional process toward ability to utilize sunflecks. This sunfleck mentality inadvertently communicates that a taxon's inherent physiological ability to use sunflecks is passively unexpressed in gaps or open habitats. This sunfleck-centric outlook does not adequately validate the bi-directional adaptive potential whereby capable plants actively acclimate to sunfleck use in understory habitats but just as actively acclimate to the excessive energy conditions of large canopy gaps and open habitats.

Interpretations from the decades of research on sunfleck use by plant leaves may be confusing because the best approach for defining species commonalities has not been identified. Rather than using successional status, growth form, or phylogeny, perhaps the use of ecological niche theory (Vandermeer 1972) would improve the outcomes. Employing a biogeography approach based on Hutchinson's niche (Hutchinson 1957) may enable a reassessment of the niche breadth of each model species. For example, $C$. micronesica occupies highly diverse habitats throughout its native range (Fig. 1). The species thrives in soils with disparate hydrological and chemical traits, from highly acid, poorly drained volcanic substrates to highly alkaline, highly permeable calcareous coralline substrates. The mature plants form the emergent canopy at one extreme of the niche range with regard to incident light, but persist permanently in deep understory 
conditions at the other extreme of the niche range. To enable this manner of fitting into biogeographical patterns, leaf development strategies of mature trees need the best leaf for each of the disparate habitats, and construct that leaf not by passively failing to express a trait that is not unneeded but by actively expressing a trait that is needed. The published reports on sunfleck use by various species where understory and gap individuals did not reveal a difference in induction traits may have been model species that exhibit an obligate relationship with narrow ecological niche requirements. In contrast, the reports where understory plants were more efficient in sunfleck use than gap plants may have been model species like $C$. micronesica that exhibit a more facultative relationship with ecological niche requirements.

Case studies based on sun-cloud transitions indicate that herbaceous species may be more responsive to light transitions with rapid adjustments in stomatal conductance, whereas woody species are less responsive as a group (Knapp and Smith 1989, 1990b). This disparity in speed of stomatal response among species causes woody species to exhibit greater surplus in transpiration and reduction in WUE during cloud cover. Some pachycaul taxa, such as cycads (Niklas et al. 2006, Niklas and Marler 2008) and Carica papaya L. (Niklas and Marler 2007), are unique and do not fit well into the woody-herbaceous dichotomy. For example, cycads and Carica papaya are dissimilar to most trees in that they do not have true wood and produce robust columnar stems comprised mostly of live parenchyma tissue (Sporne 1965, Greguss 1968, Niklas and Marler 2007, Fisher et al. 2009). Alternatively, they are dissimilar to most herbs in that they employ unique biomechanical approaches to exhibit the height and bulk of many woody tree species. Therefore, predictions of stomatal responses to sun-cloud transitions using a binary woody-herbaceous framework are difficult to formulate for these pachycaul taxa. Carica papaya plants under Guam's sky conditions exhibited a decline in WUE following sun-cloud transitions as a result of the abrupt decline in $P_{\mathrm{N}}$, but then exhibited a recovery of WUE as a result of a decline in stomatal conductance (Clemente and Marler 1996). This stomatal behavior limited $P_{\mathrm{N}}$ by the end of a 3-min cloud event, such that recovery of $P_{\mathrm{N}}$ was sluggish following the cloud-sun transitions. In contrast, C. micronesica plants exhibited the more conservative approach of woody species (Knapp and Smith 1989, 1990b, Andersen 1991) by not tracking sun-cloud transitions with a rapid stomatal response (Fig. 4). WUE did recover some during cloud cover, presumably as a result of a decrease in $E$ that resulted from decreased leaf temperature. The sustained stomatal conductance during cloud cover allowed the $C$. micronesica leaves to recover to precloud $P_{\mathrm{N}}$ within $40 \mathrm{~s}$ of the cloud-sun transition.

Cycas micronesica leaf age influenced maximum $P_{\mathrm{N}}$ and photosynthetic response to light under steady state conditions (Marler 2007). Leaf age may also influence plant responses to dynamic light conditions (Urban et al. 2008). The influence of C. micronesica leaf age on leaf responses to simulated cloud cover were subtle, primarily because the stomatal conductance responses were minimal. Although young leaves exhibited greater gas exchange and WUE than old leaves, the changes during cloud cover were similar for the two leaf ages (Fig. 4). The only difference in the reduction of the four response variables during cloud cover occurred for $E$, where $E$ of old leaves was relatively less influenced by cloud cover than $E$ of young leaves. Because of the integrating factors with other leaf traits, this did not translate to a significant difference of cloud cover on WUE. However, a slower recovery of young leaf $E$ following the cloud-sun transition caused WUE to exceed precloud conditions for a longer period of time for the young leaves compared to the old leaves.

The physical arena surrounding the sub-stomatal cavity is constructed with elegant hardware. This machinery is designed to efficiently sustain physiology that initiates primary metabolism on which the plant depends, and it harvests an energy source that originated $150.000,000 \mathrm{~km}$ away to fuel the process. Considering the elaborate choreography that is required to sustain the intricate interacting components of the anatomical and physiological processes, unstudied feedback loops and redundancies likely serve as built-in insurance to protect the integrity of the hardware. The diversity of published research outcomes is not surprising, considering these phenomena.

In closing, despite several decades of research on rapid gas-exchange responses of plant leaves to rapid light transitions, this is the first report for any cycad species to address this research agenda. Moreover, it is the first report to include any nonconifer gymnosperm with enough methodological detail to enable comparison to the literature. The results indicate that this cycad, although a gymnosperm, does not conform to the relatively slow induction times previously reported for gymnosperms. The addition of this cycad to the global data set indicates that gymnosperms as a group may not be distinct from angiosperms as a group in terms of sunfleck use. The nonwoody pachycaul stems, highly diverse ecological niche occurrences, subtropical and tropical native range, and other traits that validate the importance of cycads to contemporary plant biology research are some of the many reasons cycads should not be excluded from case studies that seek to characterize gymnosperm traits. Considering the importance of effectively utilizing sunflecks for persistence in many habitats and the globally threatened status of cycads, continued research to expand more cycad case studies should be on the agenda of physiologists, ecologists, and conservationists. 


\section{References}

Álvarez-Yépiz J.C., Búrquez A., Dovčiak M.: Ontogenetic shifts in plant-plant interactions in a rare cycad within angiosperm communities. - Oecologia 175: 725-735, 2014a.

Álvarez-Yépiz J.C., Cueva A., Dovčiak M., et al.: Ontogenetic resource-use strategies in a rare long-lived cycad along environmental gradients. - Conserv. Physiol. 2: cou034, 2014b.

Andersen P.C.: Leaf gas exchange of 11 species of fruit crops with reference to sun tracking/non-sun-tracking responses. Can. J. Plant Sci. 71: 1183-1193, 1991.

Bai K.D., Liao D.B., Jiang D.B. et al.: Photosynthetic induction in leaves of co-occurring Fagus lucida and Castanopsis lamontii saplings grown in contrasting light environments. Trees 22: 449-462, 2008.

Brantley S.T. Young D.R.: Linking light attenuation, sunflecks, and canopy architecture in mesic shrub thickets. - Plant Ecol. 206: 225-236, 2010.

Brenner E.D., Stevenson D.W., Twigg R.W.: Cycads: evolutionary innovations and the role of plant-derived neurotoxins. - Trend. Plant Sci. 8: 446-452, 2003.

Brodribb T.J., Feild T.S., Jordan G.J.: Leaf maximum photosynthetic rate and venation are linked by hydraulics. - Plant Physiol. 144: 1890-1898, 2007.

Brummitt N.A., Bachman S.P., Griffiths-Lee J. et al.: Green plants in the red: A baseline global assessment for the IUCN sampled Red List Index for plants. - PLoS ONE 10: e0135152, 2015.

Burgess A.J., Retkute R., Preston S.P. et al.: The 4-dimensional plant: Effects of wind-induced canopy movement on light fluctuations and photosynthesis. - Front. Plant Sci. 7: 1392, 2016.

Calonje M., Stevenson D.W., Stanberg L.: The World List of Cycads. Available from: http://www.cycadlist.org, 2016.

Chazdon R.L.: Sunflecks and their importance to forest understorey plants. - Adv. Ecol. Res. 18: 1-63, 1988.

Chazdon R.L., Pearcy R.W.: The importance of sunflecks for forest understory plants. - BioScience 41: 760-766, 1991.

Chen H.Y.H., Klinka K.: Light availability and photosynthesis of Pseudotsuga menziesii seedlings grown in the open and in the forest understory. - Tree Physiol. 17: 23-29, 1997.

Clark D.B., Clark D.A., Grayum M.H.: Leaf demography of a neotropical rain forest cycad, Zamia skinneri (Zamiaceae). Am. J. Bot. 79: 28-33, 1992

Clemente H.S., Marler T.E.: Drought stress influences gasexchange responses of papaya leaves to rapid light transition. J. Am. Soc. Hortic. Sci. 121: 292-295, 1996.

Fisher J.B., Lindström A., Marler T.E.: Tissue responses and solution movement after stem wounding in six Cycas species. - HortScience 44: 848-851, 2009.

Fragnière Y., Bétrisey S., Cardinaux L. et al.: Fighting their last stand? A global analysis of the distribution and conservation status of gymnosperms. - J. Biogeogr. 42: 809-820, 2015.

Garcia S., Kovař́k A.: Dancing together and separate again: gymnosperms exhibit frequent changes of fundamental $5 \mathrm{~S}$ and 35S rRNA gene (rDNA) organization. - Heredity 111: 23-33, 2013.

Goldstein G., Santiago L.S., Campanello P.I. et al.: Facing shortage or excessive light: how tropical and subtropical trees adjust their photosynthetic behavior and life history traits to a dynamic forest environment. - In: Goldstein G., Santiago L.S. (ed.): Tropical Tree Physiology, Vol. 6. Pp. 319-336. Springer,
London 2016.

Greguss P.: Xylotomy of the Living Cycad. Pp. 260. Akadémiai Kiadó, Budapest 1968.

Han Q., Yamaguchi E., Odaka N. et al.: Photosynthetic induction responses to variable light under field conditions in three species grown in the gap and understory of a Fagus crenata forest. - Tree Physiol. 19: 625-634, 1999.

Hutchinson G.E.: Concluding remarks. - Cold Spring Harb. Symp. Quant. Biol. 22: 415-427, 1957.

Knapp A.K., Smith W.K.: Influence of growth form and water relations on stomatal and photosynthetic responses to variable sunlight in subalpine plants. - Ecology 70: 1069-1082, 1989.

Knapp A.K., Smith W.K.: Contrasting stomatal responses to variable sunlight in two subalpine herbs. - Am. J. Bot. 77: 226231, 1990a.

Knapp A.K. Smith W.K.: Stomatal and photosynthetic responses to variable sunlight. - Physiol. Plantarum 78: 160-165, 1990b.

Küppers M., Timm H., Orth F. et al.: Effects of light environment and successional status on lightfleck use by understory trees of temperate and tropical forests. - Tree Physiol. 16: 69-80, 1996.

Kursar T.A., Coley P.D.: Photosynthetic induction times in shade-tolerant species with long and short-lived leaves. Oecologia 93: 165-170, 1993.

Marler T.E.: Leaf physiology of shade-grown Cycas micronesica leaves following removal of shade. - Bot. Rev. 70: 63-71, 2004

Marler T.E.: Age influences photosynthetic capacity of Cycas micronesica leaves. - Mem. New York Bot. Garden 97: 193203, 2007.

Marler T., Haynes J., Lindström A.: Cycas micronesica. The IUCN Red List of Threatened Species 2010: e.T61316 A12462113. Available from: http://dx.doi.org/10.2305/ IUCN.UK.2010-3.RLTS.T61316A12462113.en, 2010.

Marler T.E., Lawrence J.H., Cruz, G.N.: Topographic relief, wind direction, and conservation management decisions influence Cycas micronesica K.D. Hill population damage during tropical cyclone. - J. Geogr. Nat. Disasters 6: 178, 2016.

Marler T.E., Willis L.W.: Leaf gas-exchange characteristics of sixteen cycad specie. - J. Am. Soc. Hortic. Sci. 122: 38-42, 1997.

McAusland L., Vialet-Chabrand S., Davey P. et al.: Effects of kinetics of light-induced stomatal responses on photosynthesis and water-use efficiency. - New Phytol. 211: 1209-1220, 2016.

Naumburg E., Ellsworth D.S.: Photosynthetic sunfleck utilization potential of understory saplings growing under elevated $\mathrm{CO}_{2}$ in FACE. - Oecologia 122: 163-174, 2000.

Niklas K.J., Cobb E.D., Marler T.: A comparison between the record height-to-stem diameter allometries of Pachycaulis and Leptocaulis species. - Ann. Bot.-London 97: 79-83, 2006.

Niklas K.J., Marler T.E.: Carica papaya: a case study into the effects of domestication on plant vegetative growth and reproduction. - Am. J. Bot. 94: 999-1002, 2007.

Niklas K.J., Marler T.E.: Sex and population differences in the allometry of an endangered cycad species, Cycas micronesica (Cycadales). - Int. J. Plant Sci. 169: 659-665, 2008.

Norstog K.J., Nicholls T.J.: The Biology of the Cycads. Pp. 504. Cornell University Press, Ithaca, New York 1997.

Pearcy R.W.: Photosynthetic gas exchange responses of Australian tropical forest trees in canopy, gap and understory micro-environments. - Funct. Ecol. 1: 169-178, 1987. 
Pearcy R.W.: Sunflecks and photosynthesis in plant canopies. Annu. Rev. Plant Phys. 41: 421-453, 1990.

Pearcy R.W., Way D.A.: Two decades of sunfleck research: looking back to move forward. - Tree Physiol. 32: 1059-1061, 2012.

Porcar-Castell A., Palmroth S.: Modelling photosynthesis in highly dynamic environments: the case of sunflecks. - Tree Physiol. 32: 1062-1065, 2012.

Smith W.K., Knapp A.K., Reiners W.A.: Penumbral effects on sunlight penetration in plant communities. - Ecology 70: 16031609, 1989.

Soleh M.A., Tanaka Y., Kim S.Y. et al.: Identification of large variation in the photosynthetic induction response among 37 soybean [Glycine max (L.) Merr.] genotypes that is not correlated with steadystate photosynthetic capacity. Photosynth. Res. 131: 305-315, 2017.

Sporne K.R.: The Morphology of Gymnosperms. Pp. 216. Hutchinson University Library, London 1965.

Urban O., Košvancová M., Marek M.V. et al.: Induction of photosynthesis and importance of limitations during the induction phase in sun and shade leaves of five ecologically contrasting tree species from the temperate zone. - Tree Physiol. 27: 1207-1215, 2007.

Urban O., Šprtová M., Košvancová M. et al.: Comparison of photosynthetic induction and transient limitations during the induction phase in young and mature leaves from three poplar clones. - Tree Physiol. 28: 1189-1197, 2008.

Vandermeer J.H.: Niche theory. - Annu. Rev. Ecol. Syst. 3: $107-$ 132, 1972.

Vico G., Manzoni S., Palmroth S. et al.: Effects of stomatal delays on the economics of leaf gas exchange under intermittent light regimes. - New Phytol. 192: 640-652, 2011.

Way D.A., Pearcy R.W.: Sunflecks in trees and forests: from photosynthetic physiology to global change biology. - Tree Physiol. 32: 1066-1081, 2012.

Zhang Y.-J., Cao K.-F., Sack L. et al.: Extending the generality of leaf economic design principles in the cycads, an ancient lineage. - New Phytol. 206: 817-829, 2015.

Zhang Q., Chen J.-W., Li B.-G. et al.: Epiphytes and hemiepiphytes have slower photosynthetic response to lightflecks than terrestrial plants: evidence from ferns and figs. - J. Trop. Ecol. 25: 465-472, 2009. 